\title{
Experimental Investigation of performance and emission characteristics of Ethanol blended diesel with zinc oxide nanoparticles.
}

\author{
Mr.Udhaya Kumar V $V^{\# 1}$, Mr.Bharath.P ${ }^{* 2}$, Dr.John Presin Kumar ${ }^{\circledR 3}$ \\ \#B.Tech Final Year Student, Mechanical Department, Hindustan University, Chennai-Tamil Nadu, India. \\ 11udhaya5vijay@gmail.com \\ *Assistant Professor, Automobile Department, Hindustan University, Chennai-Tamil Nadu, India. \\ ${ }^{2}$ pbarath@hindustanuniv.ac.in \\ ${ }^{\circledR}$ Associate Professor, Mechanical Department, Hindustan University, Chennai-Tamil Nadu, India. \\ ${ }^{\circledR 3}$ johnpk@hindustanuniv.ac.in
}

\begin{abstract}
Diesel engines are widely used in the field of transportation and power generation because of its better fuel economy. Due to dwindling of petroleum resources suitable alternative fuel has to be replaced in the place of existing petroleum products. Global demand in thrusting researchers to focus on alternate fuel which serves better than diesel. The main work of our manuscript deals with the comparison on effect of zinc oxide nanoparticle with ethanol blended diesel in two suitable proportions. Firstly 200ppm of zinc oxide nanoparticle blended with 15\% by volume of Ethanol with Diesel (D85 E15 Z 5). Another blend with 5\% of Ethanol blended with Diesel (D95 E5 Z2) along with 500ppm of zinc oxide nanoparticle. The blend were tested in different load conditions in kirloskar single cylinder water cooled naturally aspirated compression ignition engine. The blend were compared with base diesel fuel which lead to a conclusion where there was a reduction in $\mathrm{CO}_{2}, \mathrm{CO}, \mathrm{HC}$ and there was a considerable increase in the $\mathrm{NO}_{\mathrm{x}}$, and Brake Thermal Efficiency(B.T.E).
\end{abstract}

Keyword- Zinc oxide nanoparticle, Ethanol blended diesel, Diesel engine, performance and emission.

\section{INTRODUCTION}

India has GDPA growth of $10 \%$ for the last year which in turn demands to growing industrial needs. So transporting raw materials and finished products throught the country plays a major role. The field of power production also concerned with flourishing industrial growth as per stated by honorable Prime Minister of India Mr.Nardendra Modi affirming the fact that India will become $3^{\text {rd }}$ largest economy of the world at 2030. And it will become the top 3 preferable manufacturing destination by corporate company by the end of 2020. So this directly reflects the demand for the transportation and power generation in the preceding years.

These two areas are precisely dominated by diesel engine because of their high thermal efficiency but this growing demand also reflects in the need of importing petroleum products from the other countries. So this cause triggers researchers to find a suitable alternative which serves and a better performing fuel which helps in reducing the emission and increase in the fuel efficiency. Ethanol serves as suitable alternative because it can be easily produce carbon foot print blending along with diesel will lead to a considerable amount of reduction in emission.

The practice of using nanoparticles over the years has increased the knowledge on how the nanoparticle influence the emission parameters of diesel engines. An extensive literature survey leads to a conclusion that zinc oxide nanoparticle reduces Carbon Mono Oxide (C.O.) and Hydro Carbon (H.C.) by considerable amount there by increasing the Brake Thermal Efficiency(B.T.E.) by small fraction. The objective of this experimental study is to investigate the characteristics of exhaust emission and engine's performance for two ethanol diesel blends.

\section{SYNTHESIS OF BLENDED FUEL:}

Ethanol was used to reduce the amount of carbon footprint in the fuel but in normal conditions blending of ethanol and diesel won't be completely miscible because of the surface tension between the two fuels. Inorder to make the fuel completely miscible surfactant: span $80(3 \mathrm{ml})$ was used for one liter of each blended fuel. A magnetic stirer which emphasis high-speed mixing was used to blend the ethanol and diesel.

Four blend proportions were primarily prepared, then suitable zinc oxide nano particle were added. The overall two dosages were used :one with 200ppm and other with 500ppm. The required doing level were measured by the help of precession electronic weighing scale and then the fuel were mixed by means of ultrasonic agitator. The blended fuel were given at a constant agitation of 45minutes to produce an uniform blend and then the fuel were left for phase separation process. 
TABLE I. Blend Proportions

\begin{tabular}{|c|c|c|c|}
\hline S.NO & $\begin{array}{c}\text { Diesel } \\
\text { Proportion(ml) }\end{array}$ & $\begin{array}{c}\text { Ethanol } \\
\text { Proportion(ml) }\end{array}$ & $\begin{array}{c}\text { ZnO2 Nano Particle } \\
\text { (gm) }\end{array}$ \\
\hline 1 & 950 & 50 & 0.2 \\
\hline 2 & 950 & 50 & 0.3 \\
\hline 3 & 850 & 150 & 0.3 \\
\hline 4 & 850 & 150 & 0.5 \\
\hline
\end{tabular}

It was found that blend with 0.2 and 0.5 Zinc oxide nanoparticle had a stable time period of more than one week. Those two blends were used to calculate the performance and emission characteristics.

\section{III.STABILITY DETERMINATION:}

The Two blends which had 0.2 and 0.5 gm was found to be the most stable fuel, these Two Blends showed meager phase separation of ethanol and Diesel after one week. In order to find the dispersion of Nano particles in the Blends SEM(Scanning Electron Microscope) test was carried out, Both the blends showed different type of Nano particle dispersion.

TABLE II. Scanning Electron Microscope specification.

\begin{tabular}{|c|c|}
\hline Parameters & Details \\
\hline ACC Voltage & 0.3 to $30 \mathrm{KV}$ \\
\hline Magnification & $5 \mathrm{X}$ to $300,000 \mathrm{X}$ \\
\hline Resolution & 3.0nm (30Kv HV mode) \\
& 10nm (3Kv LVmode) \\
& $4.0 \mathrm{~nm}$ (30 Kv LVmode) \\
\hline Standard detectors & SE ,BSE \\
\hline Specimen stage & Fully motorized, 100/50 XY movements \\
\hline PC & Latest PIV \\
\hline Coating Unit & Ion sputter coater with Gold target \\
\hline Chamber viewing & IRCCD camera \\
\hline EDS detector system & LN2 free, Peltier cooled, $139 \mathrm{eV}$ \\
\hline
\end{tabular}
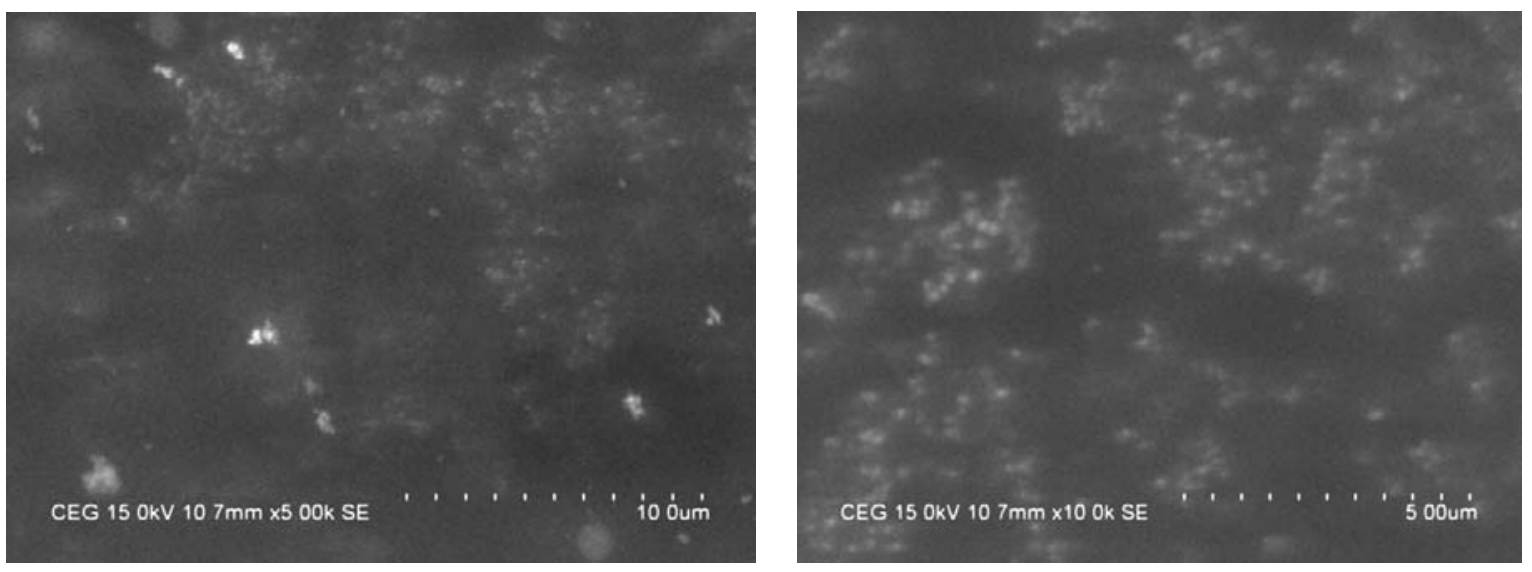

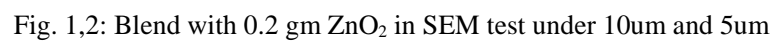

The first blend showed moreover a even dispersion of nano particle under 10um, but there are some lumps of Nanoparticles which are still not completely miscible with the fuel. These lumps will results in settling back in the combustion chamber which would result in acting as a heat sink which will be helpful in higher operating condition but in prolonged usage it will result in engine starting problem, due to the loss in Transcent Temperature. 

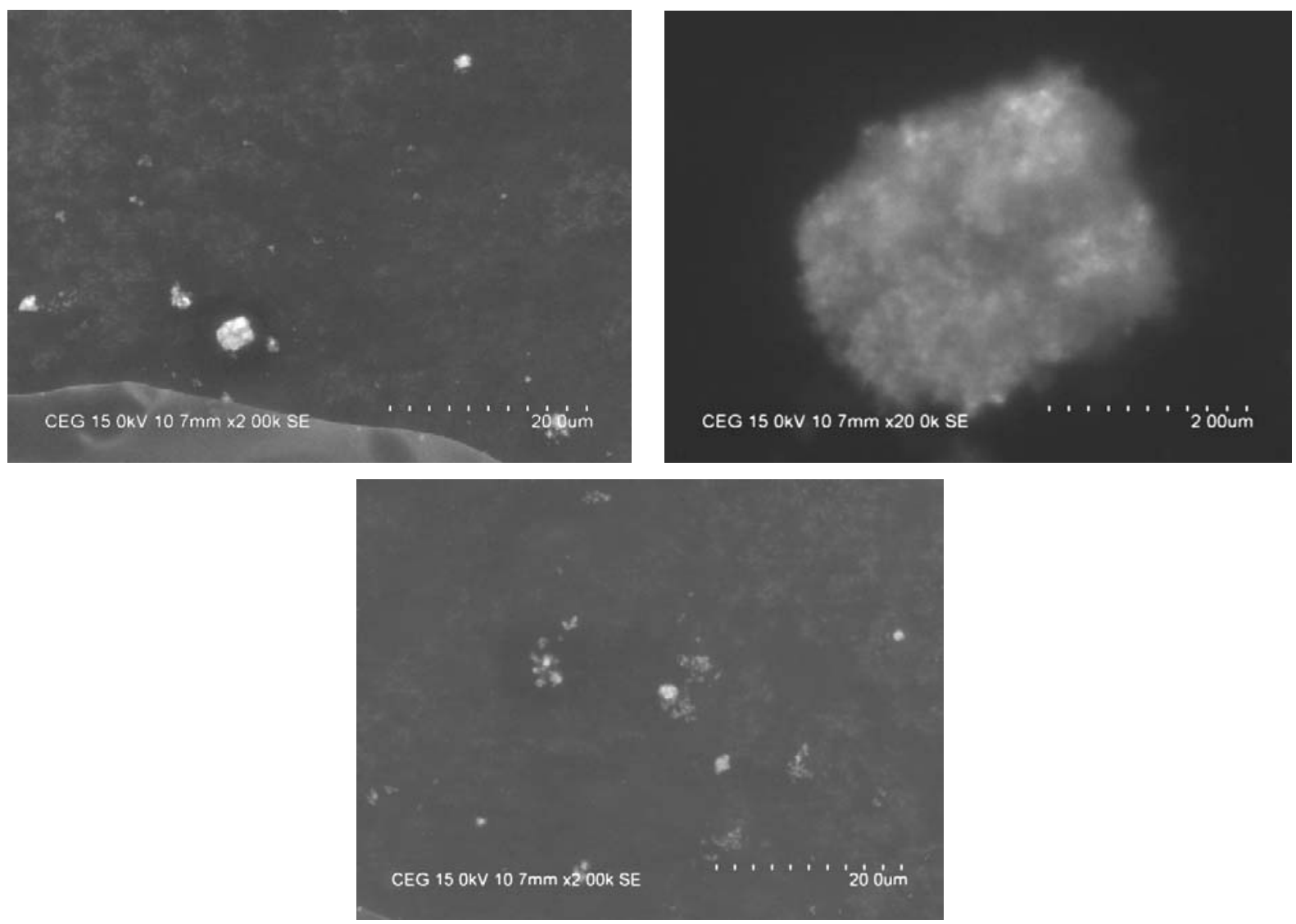

Fig. 3, 4, 5: Blend with 0.5gm $\mathrm{ZnO}_{2}$ in SEM test under 20um and 2um.

The Second Blend which has more quantity of Zinc oxide particle showed lot of coagulation and uneven dispersion of the particles. This fuel blends will result in uneven emission graphs, due to the irregularity found through out the fuel. This fuel would also result in cloging of injectors and it can be prevented by changing the Diesel filter regularly. Since the Nano particles are not spread evenly they will not help in reducing the operating temperature hence $\mathrm{NO}_{\mathrm{x}}$ parameter will be high for these fuels.

\section{Experimental Setup:}

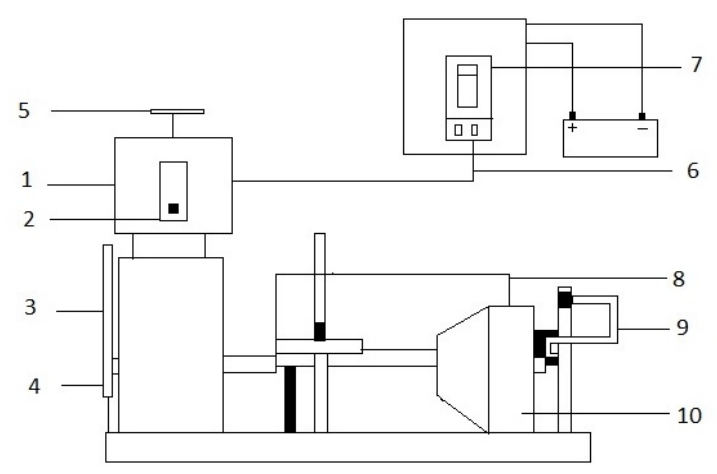

Fig. 3 : Diagram of Experimental Apparatus. 
TABLE III. Engine Parts

\begin{tabular}{|c|l|}
\hline NO & Description \\
\hline 1. & VCR Engine \\
\hline 2. & Pressure Sensor \\
\hline 3. & Crank angle encoder \\
\hline 4. & Speed Sensor \\
\hline 5. & Air flow sensor \\
\hline 6. & Exhaust gas line \\
\hline 7. & Gas Analyzer \\
\hline 8. & Gas Calorimeter \\
\hline 9. & Load Sensor \\
\hline 10. & Dynamometer \\
\hline
\end{tabular}

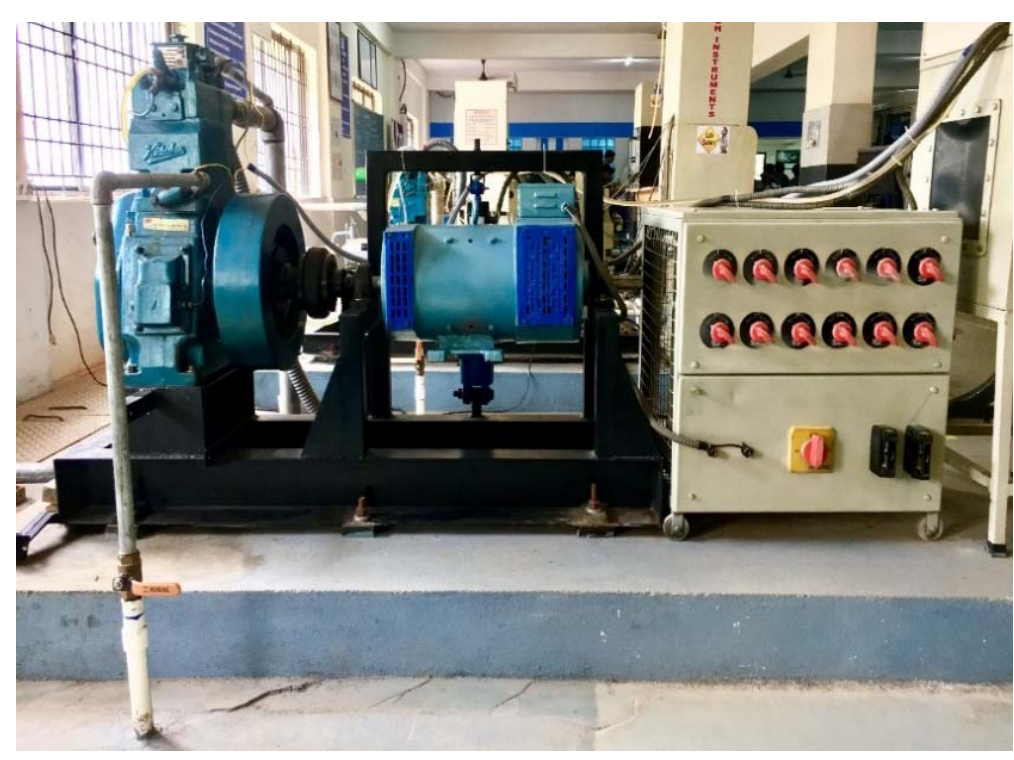

Fig. 6: Kirloskar DM 10 Engine

Our experiment is conducted in Hindustan Institute of Technology and Science,(Chennai) Single cylinder water cooled naturally aspirated compression ignition engine was used to perform the test where the engine has maximum Horse power(H.P.) of 10h.p. and the output shaft is connected to electrical dynamometer which has maximum capacity of 24 amps. The engine uses mechanical injector and it is a constant engine which is designed to run at $1500 \mathrm{rpm}$.

TABLE IV. Engine Specification.

\begin{tabular}{|l|l|}
\hline Make \& Model & Kirloskar DM 10 \\
\hline Bore/Stroke & $102 * 116 \mathrm{~mm}$ \\
\hline Speed & 1500 \\
\hline B.H.P & $10 \mathrm{hp}$ \\
\hline Swept Volume & $661 \mathrm{cc}$ \\
\hline Compression Ratio Range & $17.5: 1$ \\
\hline Fuel & Diesel \\
\hline Torque & $0.048 \mathrm{KN}-\mathrm{m}$ \\
\hline Dynamometer & Electrical \\
\hline
\end{tabular}

Atlon 5 gas analyzer was used to measure the emission parameter of the exhaust gas. This gas analysis measures 5 parameters (Carbon Mono-oxide(CO), Carbon Dioxide $\left(\mathrm{CO}_{2}\right)$, Hydro-Carbon( $\left.\mathrm{HC}\right)$, Oxides of Nitrogen $\left(\mathrm{NO}_{\mathrm{x}}\right)$ and Oxygen $\left(\mathrm{O}_{2}\right)$. 
TABLE V. Gas Analyzer Specification.

\begin{tabular}{|l|l|}
\hline Make & AVI \\
\hline Model & DIGAS 444 \\
\hline Display & LCD \\
\hline Interface & RS 232 \\
\hline Power Consumption & 25 Watts \\
\hline Operating Voltage & 230Volt $55 \mathrm{~Hz}$ \\
\hline
\end{tabular}

In order to analyze the performance and emission characteristics the (D85 E15 Z2), (D95 E5 Z5) were introduced to engine in all quarter, half, three fourth and full load conditions. And the required parameters are recorded.

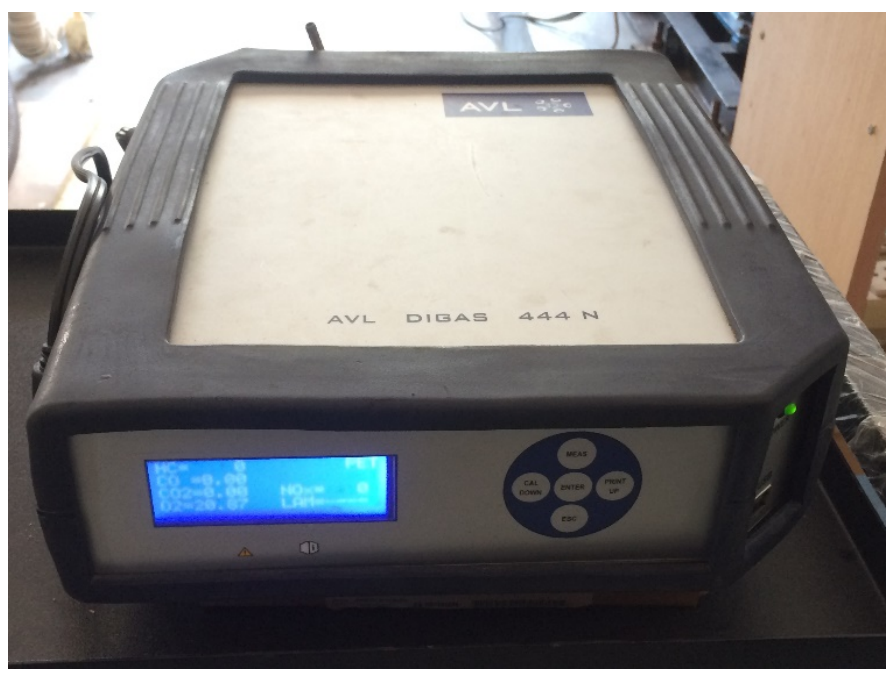

Fig. 7: Atlon Gas analyzer

All title and author details must be in single-column format and must be centered.

\section{IV.RESULTS AND DISCUSSION:}

ENGINE PERFORMANCE:

When the two blends (D95 E5 Z2), (D85 E15 Z5) were tested, the latter blend which has more nanoparticle produced slightly higher Brake Thermal Efficiency which was around $2 \%$ this is because of the presence of higher oxygen content in the blend. This actually influences better combution characteristics. The first blend which has a only $5 \%$ of ethanol, the efficiency drops in part load and in full load conditions the efficiency eclipses the base fuel reading. There was a marginal increase of 1\% BHP in full load condition.

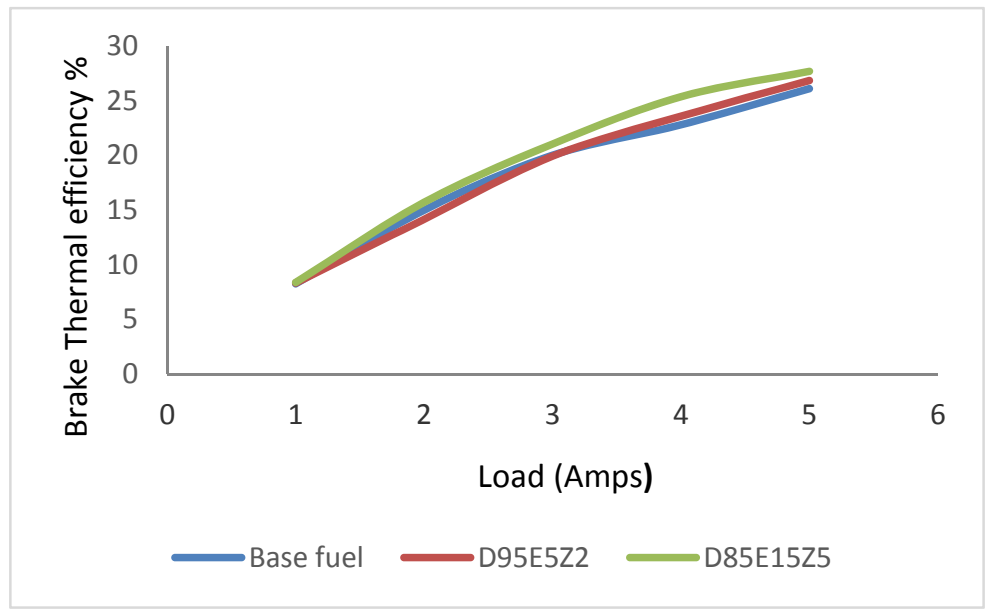

Fig. 8: Comparison of Base fuel with D95E5Z2 and D85E15Z5 for Break Thermal Efficiency and load 
Engine performance directly influences the total fuel consumption of each blend as the latter blend which has more ethanol content consumes less fuel when compared with base fuel because of higher combustion efficiency. The overall Total fuel consumption of both blends in part and full load was found to be 2 to 3 \% less compared with base diesel reading. But at low loads the Total Fuel Consumption of the blended fuels were high due to the low calorific value of the fuel.

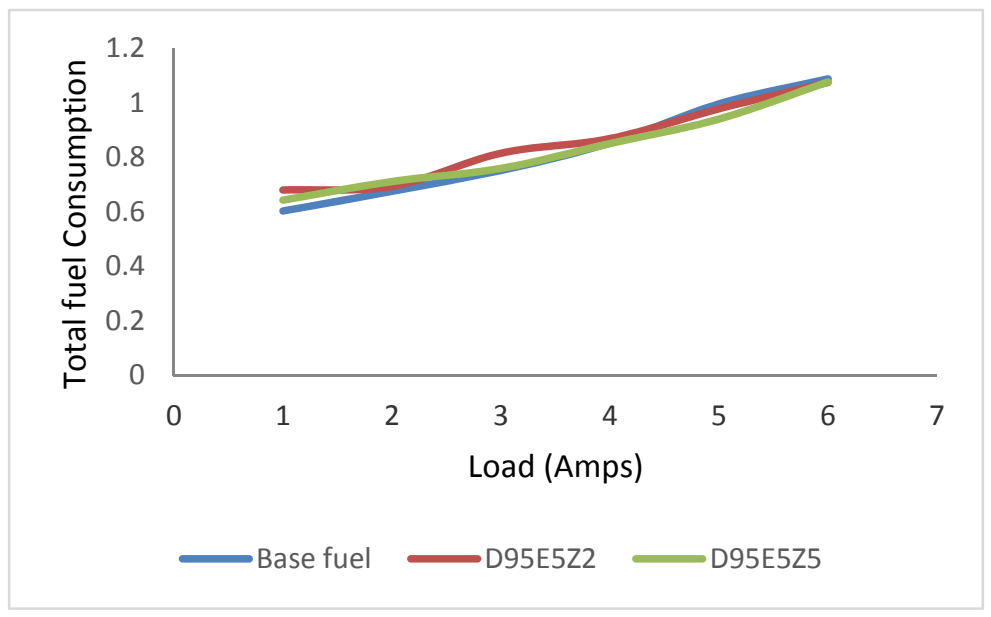

Fig. 9: Comparison of Base fuel with D95E5Z2 and D85E15Z5 for Total Fuel Consumption and Load.

\section{EMISSION CHARACTERISTICS :}

Carbon di-oxide emission of the blended fuel found to be 10 to $15 \%$ higher than the base fuel reading at full load conditions. At low loads and part load condition there was a marginal increase of within $5 \%$ this is because of effect of nanoparticle which interact with combustion at low loads the influence of nanoparticle is high. At high loads since more quantity of fuel is injected more $\mathrm{CO}_{2}$ is produced.

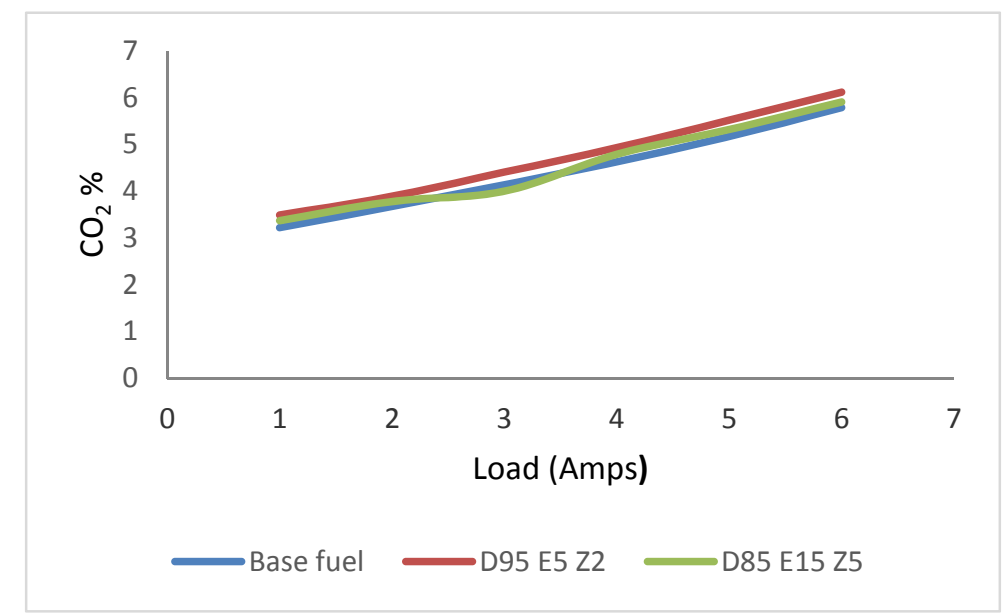

Fig. 10: Comparison of Base fuel with D95E5Z2 and D85E15Z5 for Carbondi-oxide and load

Oxide of Nitrogen emission for the blended fuel found to be to $9 \%$ higher than the base fuel reading at full load conditions. At low loads and part load condition there was a marginal increase of within $15 \%$ this is because of effect of better combustion characteristics which leads to higher operating temperatures which is influenced by the presence of additional oxygen in the blend Nanoparticle which acts as a heat sink reduces the formation of $\mathrm{NO}_{\mathrm{x}}$. But still it goes on to be higher than the base fuel reading. 


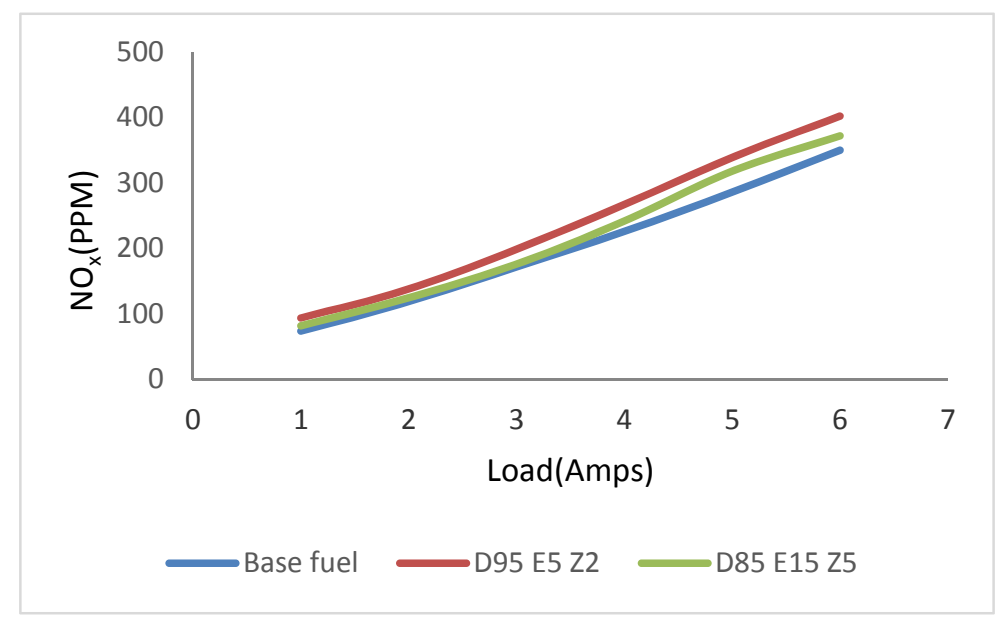

Fig. 11: Comparison of Base fuel with D95E5Z2 and D85E15Z5 for Oxides fo Nitrogen and Load.

Hydro-carbon which is primarily formed because of incomplete combustion, since the combustion has been improved in the general fuel the amount of (HC) formed was found to be less in all load conditions in the blended fuel. The average reduction of $\mathrm{HC}$ is found to be $30 \%$ and $15 \%$ respectively.

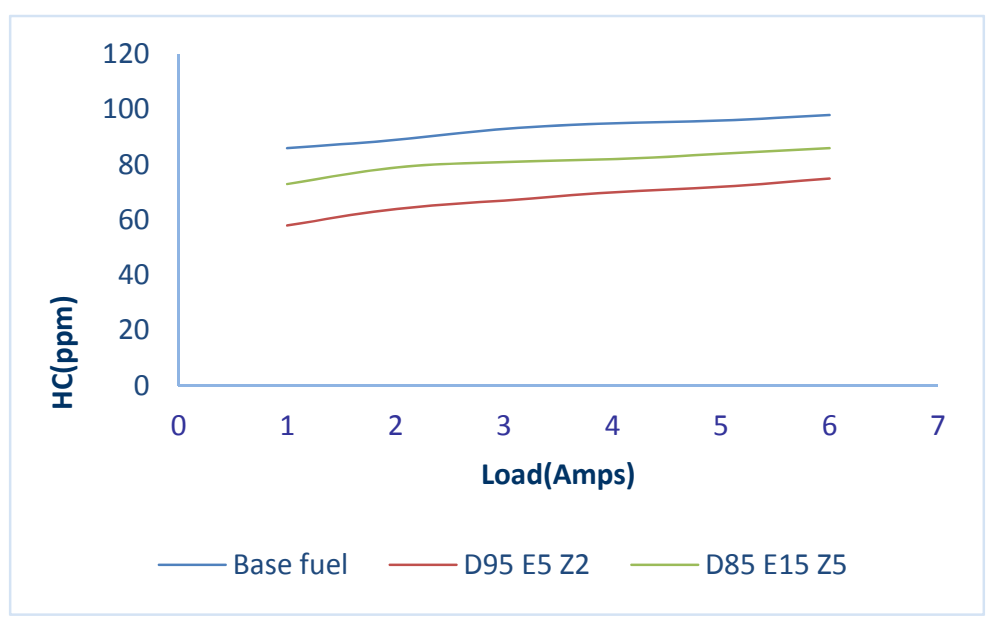

Fig. 12: Comparison of Base fuel with D95E5Z2 and D85E15Z5 for Hydro-carbon and load.

CO formation is primarily because of unavailability of oxygen the blended fuels which has better oxygen content helps influencing in the complete combustion which results in overall decrease in the CO emission by upto $11 \%$ in all load conditions

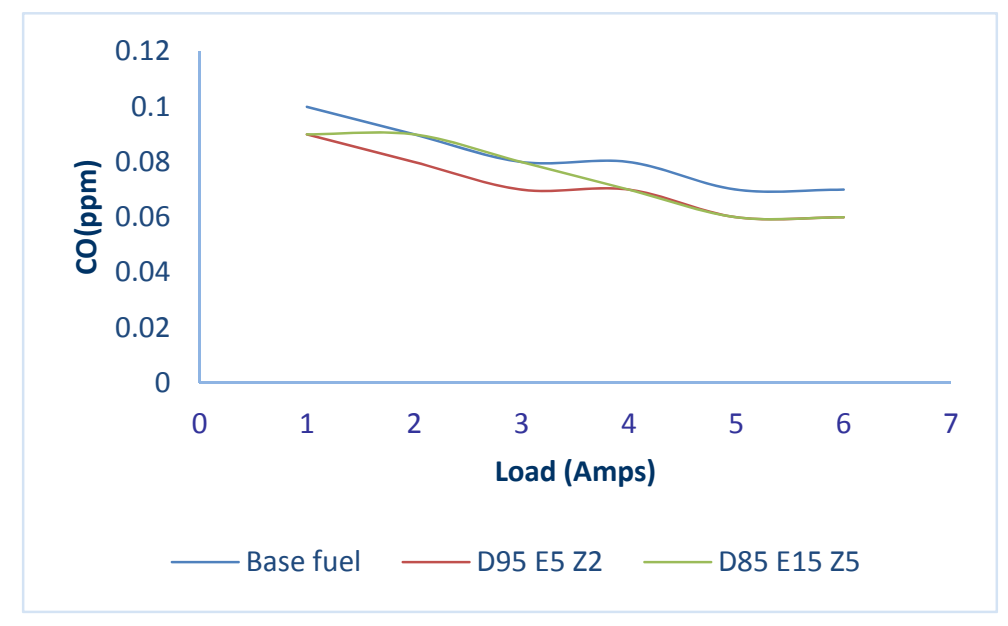

Fig. 13: Comparison of Base fuel with D95E5Z2 and D85E15Z5 for Carbon mono-oxide and Load. 


\section{Conclusion:}

The performance and emission characteristics for the blended fuel (D95 E5 Z2), (D85 E15 Z5) which was tested in a single cylinder compression ignition engine are summarized as follows :

- $\quad 2 \%$ increase in Break Thermal Efficiency was found in part load conditions and $1 \%$ increase in full load condition for the blended fuels.

- In a comparative note with base diesel reading there was around 2 to $3 \%$ decrease in the Total fuel consumption in part and full load condition of the blended fuels.

- While the $\mathrm{CO}_{2}$ footprint in the blended fuel were 10 to $15 \%$ increase when compared to the base fuel reading at full load condition.

- Averagely the reduction of HC in the blended fuel was found to be 30 to $15 \%$ for the fuel blends.

- Thus a overall decrease in the CO emissions was $11 \%$ in all load conditions for the blends.

\section{VI.REFERNCE:}

[1] Li Xiaolu , Chen Hongyan , Zhu Zhiyong, Huang Zhen. "Study of combustion and emission characteristics of a diesel engine operated with dimethyl carbonate” 2005, Energy Conversion and Management 47 (2006) 1438-1448.

[2] Gong Yanfeng, Liu Shenghua , Guo Hejun , Hu Tiegang, Zhou Longbao. “A new diesel oxygenate additive and its effects on engine combustion and emissions” 2007, Applied Thermal Engineering 27 (2007) 202-207.

[3] Sateesh Yalaravathi , Anil kumar.Chintalaudi and Satya Dev. "Performance and Emission Analysis of Diesel Engine Using Oxygenated compounds” International Journal of Advanced of Diesel Science and Technology Vol.61. (2013) pp.9-16.

[4] R. Manikandan, Sethuraman. "Experimental Investigation of Nano Additive Ceric Oxide(Ceo 2$)$ - Ethanol Blend on single cylinder four storke Diesel Engine” International Journal of Recent Development in Engineering and Technology Volume 3, Issue 2 , ISSN 2347 6435.

[5] Abbas Ali Taghipoor Bafghi, Hosien Bakhoda, Fateme kohdaei Chegeni "Effects of Cerium Oxide Nanoparticle Addition in Diesel and Diesel-Biodiesel Blends on the Performance Characteristics of a C.I. Engine" (2015)International Journal of Mechanical,Aerospace, Industrial, Mechatronic and Manufacturing Engineering. Vol.9,No.8

[6] Sungyong Park, Hwanam Kim and Byungchul choi. "Emission Characteristics of exhaust gases and nanoparticles from a diesel engine with biodiesel- diesel blended fuel” Journal of Mechanical Science and Technology (2005) 2555-2564.

[7] Website: www.makeinindia.com

\section{AUTHOR PROFILE}

Udhaya Kumar.V, B.Tech (Mechanical Engineering) Final Year Student, Hindustan University,Padur, Chennai, India. Mail I-D- udhaya5vijay@gmail.com, Contact No - 7708263285.

Bharath.P, Assitant Professor - Automobile Department, Hindustan University, Padur Chennai, India. Mail I-D- pbarath@hindustanuniv.ac.in, Contact No- 9952258688

Dr.John Presin Kumar, Associate Professor, Mechanical Department, Hindustan University Chennai-Tamil Nadu, India. Mail I-D - johnpk@hindustanuniv.ac.in, Contact No - 9489651375 